
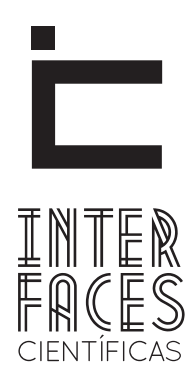

DIREITO

\title{
EUTANÁSIA NO DIREITO PENAL: OS ASPECTOS JURÍDICOS DO HOMICÍDIO PIEDOSO
}

\author{
EUTHANASIA: THE LEGAL ASPECTS OF PIOUS HOMICIDE
}

EUTANASIA EN DERECHO PENAL: ASPECTOS JURÍDICOS DE ASESINATO PIADOSO

\section{RESUMO}

0 artigo em questão investiga as consequências da aplicação da eutanásia perante o ordenamento jurídico brasileiro, mostrando, além do tratamento dado à prática pelo direito penal, os fatores que a criminalizam. Desta forma, é possível discutir a violação e a disponibilidade de um dos principais direitos fundamentais da Constituição Federal de 1988: o direito à vida. Dentro desse contexto, o questionamento a ser feito é: A eutanásia é o direito a uma morte digna ou um crime? E quando se trata de uma escolha da vítima, o que acontece com o aparente assassino? Até que ponto o direito a vida é indisponível? Partindo desse princípio, esta pesquisa tem como objetivos: investigar os fatores que criminalizam a eutanásia, compreender as consequências dessa prática perante o direito penal pátrio e debater o papel ocupado pelo ato na sociedade: seria um crime ou ato de piedade?

\section{PALAVRAS-CHAVE}

Eutanásia. Direitos Humanos. Direito à Vida. Homicídio. 


\section{ABSTRACT}

The article in question investigates the consequences of the application of euthanasia to the Brazilian legal system, showing, besides the treatment of the practice by criminal law, the factors that criminalize. Therefore, is possible to discuss the violation and the availability of one of the main fundamental rights of the Constitution of 1988: the right to life. In this context, the question to be posed is: Euthanasia is the right to a dignified death or a crime? And when it comes to a choice of the victim, what happens to the apparent

\section{RESUMEN}

El artículo en cuestión investiga las consecuencias de la aplicación de la eutanasia al sistema jurídico brasileño, mostrando, además del tratamiento de la práctica por la ley penal, los factores que penalizan. Por lo tanto, es posible hablar de la violación y la disponibilidad de uno de los principales derechos fundamentales de la Constitución de 1988: el derecho a la vida. En este contexto, la cuestión que se plantea es: La eutanasia es el derecho a una muerte digna o un delito? Y cuando se trata de una elección de la víctima, lo que pasa con el asesino aparente? ¿En qué medida el derecho a la vida no está dispo- killer? To what extent the right to life is unavailable? Based on this principle, this article aims to: investigate the factors that criminalize euthanasia, understand the consequences of this practice to the parental criminal law and discuss the role played by the act in society: it would be a crime or act of mercy?

\section{KEYWORDS}

Euthanasia. Human rights. Right to life. Homicide. nible? Sobre la base de este principio, la presente investigación tiene como objetivo: investigar los factores que penalizan la eutanasia, comprender las consecuencias de esta práctica a la ley penal de los padres y discutir el papel desempeñado por el hecho en la sociedad: sería un crimen o un acto de misericordia?

\section{PALABRAS CLAVE}

la eutanasia, los derechos humanos, el derecho a la vida, asesinato. 


\section{INTRODUCC̆̃O}

A eutanásia é um fenômeno bastante antigo e sua própria nomenclatura vem do grego e significa boa morte, ou de acordo com algumas traduções, morte apropriada. Sendo assim, como o nome já nos diz, o intuito da eutanásia é provocar uma morte menos dolorosa para aquele que se encontra em estado de profundo sofrimento. É um encurtamento necessário de uma vida que não possui a dignidade necessária para o indivíduo querer continuar vivo. É um homicídio motivado por pura compaixão e piedade.

Por muito tempo, o termo foi empregado abrangendo os mais diversos tipos de procedimento, comissivos ou omissivos, em pacientes que, mesmo doentes, encontravam-se em situações com níveis diferentes de sofrimento (ABREU, 2015). Hoje em dia, o conceito de eutanásia popularmente conhecido compreende a eutanásia ativa, que é aquela em que realmente existe uma ação para findar a vida do paciente enfermo.

Já a eutanásia passiva - ortotanásia - consiste em uma omissão. Nesse segundo tipo, os meios que sustentam a vida do paciente são retirados, privando-o de um tratamento que já não fazia tanto efeito assim. Dessa forma, o médico apenas regulará aspectos naturais e deixará que a vida do paciente se estenda pelo tempo que seu corpo aguentar, sem utilização de aparelhos ou mecanismos que prolonguem sua vida. Se o tratamento se prolongar sem obtenção de resultados, havendo também uma extensão do sofrimento do paciente, estamos frente à distanásia. É desse tipo de procedimento que surge a ideia de vida vegetativa: o paciente não responde aos estímulos, mas sua vida continua sendo prolongada, utilizando-se de meio artificiais. (GONÇALVES, 2012)

Quanto ao consentimento do paciente, se faz necessário citar também outros três tipos de eutanásia. A eutanásia voluntária é aquela em que existe uma vontade real do paciente. Nesse tipo, o paciente quer realmente morrer para que seu sofrimento - que não pode ser tratado - seja aliviado e, por isso, pede ajuda a alguém. A eutanásia voluntária é também deno- minada de suicídio assistido. A segunda espécie é a chamada eutanásia involuntária. Nesta, temos a completa negação do paciente, ou seja, ele não quer morrer, não deseja a sua morte e esta é provocada contra a sua vontade. Esse tipo de eutanásia, praticada em larga escala pela medicina nazista, pode e deve ser punida, pois se trata de homicídio.

Por fim, o terceiro tipo de eutanásia quanto ao consentimento do paciente é a eutanásia não-voluntária, que, por sua vez, é aquela em que o paciente não está consciente e, por isso, não pode fazer escolhas ou tomar decisões. Geralmente, é levada em consideração a escolha da família em diminuir o sofrimento de alguém que não responde mais aos estímulos médicos (ABREU, 2015).

Apesar de hoje em dia, em grande parte dos países, o método não ser visto com bons olhos, na Antiguidade, a eutanásia era bem vista e, até mesmo, estimulada. Na Índia dos tempos antigos, os doentes terminais eram ultimados no Ganges, para que fossem poupados do sofrimento que uma morte incerta os causaria. Durante a época das crucificações, em Roma, era dada aos condenados uma bebida que os induzia a um sono profundo e prolongado, fazendo com que o crucificado morresse insensivelmente, sem dores e sem exposição à crueldade. A prática também era frequente na Grécia antiga, onde os espartanos matavam os pobres, raquíticos e desprovidos de valor vital, ao invés de deixá-los viver sem as mínimas condições de dignidade (MENEZES, 1077)

Independentemente de toda a bondade supostamente envolvida na prática, a eutanásia vai de encontro a um dos maiores - senão o maior - principio fundamental: a vida. Atualmente, poucos são os países que não criminalizam o método e, preponderantemente, a eutanásia esbarra na ética e nos dogmas religiosos, encontrando barreiras para ser praticada ao redor do mundo. No Brasil, que, em tese, adota a laicidade do Estado, mas condena grande parte das convenções opostas às cristãs, a atividade ainda é 
condenada e tratada como homicídio puro e simples o ordenamento jurídico pátrio ainda não possui legislação ou qualquer tipificação especial que regularize ou regulamente a eutanásia.

Após observar a forma como a eutanásia é tratada pela sociedade surge o interesse pelo tema, que possui uma relevância indiscutível. Seja por motivos religiosos, ou por motivos políticos, o assunto ainda é um tabu, o que dificulta a discussão, o esclarecimento de pontos importantes acerca do tópico e a aplicação do método quando se faz necessário, tornando a matéria extremamente pertinente para a sociedade em que vivemos.

É fato que no ordenamento jurídico existe a prevalência do direito à vida, sendo ele o objeto de discussão desse artigo. A discussão será pautada no inviolável e indisponível direito de viver, que, em muitos casos, torna-se o dever de viver. Teria o paciente terminal poder de dispor do direito à vida em busca de uma morte digna ou quem o ajudasse nessa prática seria considerado um criminoso?

\section{EUTANÁSIA NO DIREITO PENAL}

O ordenamento jurídico brasileiro se subdivide em vários ramos do direito. 0 direito civil, constitucional, administrativo, penal, processual, internacional etc., são juntos, um grande sistema que se comunica e se completa, formando uma só sistemática de organização social. Dentre os ramos citados, temos o direito penal que nada mais é do que um mecanismo que pretende preservar a paz e a harmonia entre os indivíduos, por meio de controle social.

Ao se querer descrever a posição do Direito Penal e as suas tarefas (ou seja, praticar a teoria do Direito Penal), então o conceito do controle social pode servir como relevo. A posição do Sistema de Direito Penal se encontra no campo de controle social, o Sistema de Direito Penal é uma de suas partes. (HASSEMER, 2007, p. 112).

Desta forma, fica evidente que é de responsabilidade do Direito Penal selecionar condutas e práticas que retirem o equilíbrio social e incriminá-las por meio da criação de leis - para o principio da legalidade, não há crime sem lei anterior que o defina, nem pena sem prévia cominação legal. Trata-se do que chamamos de novatio legis incriminadora: uma conduta, que, até então, não era considerada ofensiva para o bem comum, torna-se um fato penalmente típico. Nas palavras de Estefam (2015, p. 231) a novatio legis incriminadora é quando "uma conduta penalmente atípica passa a ser definida como crime ou contravenção".

No que diz respeito ao título deste artigo, as legislações penais brasileiras nunca se interessaram em dispor sobre a eutanásia. Na vigência do código penal de 1830, a pena aplicada ao método em discussão era a do crime de auxílio em suicídio. A conduta de equiparar as penas das duas ações é ampla e duramente criticada pela doutrina penalista, pois se tratam de condutas autônomas e diferentes quanto aos seus elementos principais.

O que diferencia a eutanásia do suicídio assistido é quem realiza o ato, no caso da eutanásia o pedido é feito para que alguém execute a ação que vai levar à morte; no suicídio assistido é o próprio paciente que realiza 0 ato, embora necessite de ajuda para realiza-lo, e nisto difere do suicídio, em que esta ajuda não é solicitada. (KOVÁCS, 2003, p. 196).

As codificações seguintes, inclusive a de 1940, que mantém sua vigência até hoje, continuam com a mesma linha de raciocínio acerca do assunto, fazendo com que o jurista aplicador da lei tenha que equiparar condutas, apesar de serem, como já observados anteriormente, atos distintos. A partir disso, podemos atestar a inexistência de tipo penal incriminador específico para a eutanásia - o que não significa dizer que a prática é legalizada.

É de entendimento geral na doutrina que quem pratica a eutanásia deve ter a pena submetida ao art. 121 do Código Penal Brasileiro. Tal percepção leva a prática a ser compreendida como homicídio. Contudo, deve-se levar em consideração o $\$ 1^{\circ}$ do citado dispositivo legal, que diz respeito ao que se conveniou chamar de homicídio privilegiado. É preciso que o 
aplicador da lei considere o palpável sentimento de compaixão - ou seja, o relevante valor moral descrito no tipo penal - que, teoricamente, deve existir na prática da eutanásia, como ensina Jesus (2001, p. 10) ao dizer que "a eutanásia é disciplinada como causa de diminuição de pena, dado o sujeito agir por compaixão, a pedido da vítima, imputável e maior, para abreviar-lhe sofrimento físico insuportável, em razão de doença grave".

Se a piedade envolvida no ato for devidamente comprovada, a pena - que vai de 6 a 20 anos - pode ser diminuída de um sexto a um terço.

Qualquer pessoa pode ser vítima de homicídio, conforme acima mencionado, inclusive não importando o grau de vitalidade. Tanto o ser humano saudável como o moribundo podem ser vítimas de homicídio. No atual estágio do ordenamento jurídico brasileiro a chamada “eutanásia” configura crime de homicídio. 0 máximo que pode ocorrer em casos que tais é o reconhecimento de uma redução de pena devido à configuração do chamado "homicídio privilegiado" (art. 121, §1, CP). (CABETTE, 2012, p. 10).

É de extrema importância que se faça lembrar que a anuência do paciente terminal é de extrema irrelevância, juridicamente falando, e não afasta a existência do crime. Ou seja, a prática da eutanásia com o consentimento do paciente apenas poderia desqualificar o crime para o tipo penal presente no art. 122 - induzimento, instigação ou auxilio ao suicídio - e, desta forma, atenuar ainda mais a pena do autor, mas, de forma alguma, viria a ser uma excludente de ilicitude. Ainda que o consentimento exista, livre e consciente, a conduta do autor continua incriminada perante o direito penal.

É preciso mencionar ainda nesse capítulo a abordagem dada à eutanásia no anteprojeto do Código Penal brasileiro:

Ao tratar do delito de homicídio, a Comissão descreveu a eutanásia ativa como causa de diminuição de pena no $\S 3^{\circ}$ do art. 121 "Se o autor do crime é cônjuge, companheiro, ascendente, descendente, irmão ou pessoa ligada por estreitos laços de afeição à vítima, e agiu por compaixão, a pedido desta, imputável e maior de dezoito anos, para abreviar-lhe sofrimento físico insuportável, em razão de doença grave e em estado terminal, devidamente diagnosticada: Pena - reclusão, de dois a cindo anos". Já em relação à ortotanásia, a Comissão introduziu-a no $\S 4^{\circ}$ do referido art. 121, como excludente de antijuridicidade, "Não constitui crime deixar de manter a vida de alguém por meio artificial, se previamente atestada por dois médicos a morte como iminente e inevitável, e desde que haja consentimento do paciente ou, em sua impossibilidade, de cônjuge, companheiro, ascendente, descendente ou irmão". (GONÇALVES, 2012, ON-LINE).

Por fim, é importante entender e refletir sobre o tratamento destinado à eutanásia no direito penal pátrio: não existe legislação específica sobre o assunto e o projeto existente está longe de se tornar uma realidade. A falta de discussão sobre o tema é, para muitos estudiosos, um descaso do nosso ordenamento jurídico, pois se trata de um tema importante, que vem cada dia mais sendo discutido pelos meios midiáticos e, portanto, precisa de legislação especifica, não podendo continuar sendo encaixada no artigo de homicídio, pois, evidentemente, trata-se de condutas motivadas por causas distintas.

\section{FATORES QUE CRIMINALIZAM A EUTANÁSIA}

O ordenamento jurídico brasileiro conta com a Constituição Federal de 1988 como carta magna. Isso quer dizer que, ao imaginarmos tal ordenamento como uma pirâmide - popularmente chamada de pirâmide normativa de Hans Kelsen -, a Constituição seria o seu topo e as demais normas seriam os níveis restantes da pirâmide. Desta forma, a Constituição teria uma força que irradiaria de cima para baixo. Num país que conta com essa formatação constitucional, existe um escalonamento de normas, ou, como dizem os doutrinadores, uma verdadeira verticalidade hierárquica. Com relação a esse tópico, Lenza (2014, p. 88) diz que esta verticalidade hierárquica nada mais é do que "uma norma, de hierarquia inferior, busca o seu fundamento de validade na norma superior e esta, na seguinte, até chegar à 
Constituição, que é o fundamento de validade de todo o sistema infraconstitucional".

É fato, partindo dessa premissa, que a Constituição Federal, em seu artigo $5^{\circ}$, elenca os direitos e garantias fundamentais que devem ser acessíveis a todo cidadão brasileiro. Todavia, é majoritário o entendimento da doutrina que os direitos contidos na Constituição não se restringem ao rol taxativo do tipo constitucional supracitado. 0 rol taxativo se torna exemplificativo ao lembrarmos que a Constituição Federal de 1988 possui princípios implícitos em sua própria formação.

\begin{abstract}
Os direitos individuais são aqueles conferidos ao indivíduo para protegê-lo contra o arbítrio do Estado ou de outros particulares (direitos de defesa ou direitos de resistência). As garantias individuais, por sua vez, são os instrumentos para assegurar o exercício desses direitos. Os direitos e garantias individuais, apesar de consagrados de forma sistemática no art. $5 .^{\circ}$ da Constituição brasileira de 1988, não se restringem a esse dispositivo, encontrando-se espalhados por toda a Constituição (NOVELINO, 2014, p. 26)
\end{abstract}

Esses princípios traçam um estado ideal de como as coisas devem ser e, por isso, tem a mesma força normativa dos direitos e garantias elencados no artigo $5^{\circ}$. Faz-se necessário lembrar que, apesar de parecerem, os princípios constitucionais, bem como os direitos e garantias fundamentais, não são ilimitados. Não existe direito absoluto, muito menos principio irrefutável.

$\mathrm{Na}$ maioria das vezes, os princípios e direitos fundamentais encontram seus limites em outros princípios, ou em outros direitos. Quando isso ocorre, torna-se necessária a utilização, pelo legislador, de - ironicamente - novos princípios. 0 principio da relatividade prega que, como dito anteriormente, não existe direito absoluto. Todos os direitos, normas ou princípios encontrariam limitações em outros de espécie similar. Já o principio da concordância, prática popularmente conhecida como principio da harmonização, aduz que, ao menos em campo abstrato, as normas e princípios possuem a mesma força normativa e o que deve ser feito quando duas ou mais normas entram em conflito é a redução gradativa de cada uma delas para a solução do caso concreto.

\begin{abstract}
O campo de eleição do princípio da concordância prática tem sido até agora o dos direitos fundamentais (colisão entre direitos fundamentais ou entre direitos fundamentais e bens jurídicos constitucionalmente protegidos). Subjacente a este princípio está a ideia do igual valor dos bens constitucionais (e não uma diferença de hierarquia) que impede, como solução, o sacrifício de uns em relação aos outros, e impõe o estabelecimento de limites e condicionamentos recíprocos de forma a conseguir uma harmonização ou concordância prática entre estes bens. (CANOTILHO, 1993, p. 228 APUD LENZA, 2014, p. 172).
\end{abstract}

Isto posto, fica fácil compreender que toda decisão relacionada a qualquer assunto de grande interesse social deve ser interpretada perante a luz da Constituição e de seus princípios implícitos. Com relação à eutanásia não poderia ser diferente, pois, como já visto anteriormente, trata-se de um assunto que possui não só relevância social, como também relevância jurídica e, até mesmo, política.

Quando um ato - social ou jurídico - macula algum dos princípios constitucionais, ele deve ser impugnado. Como dito no capítulo anterior, o entendimento atual compara a eutanásia ao homicídio, imputando-lhe, inclusive, a pena do homicídio privilegiado. Esse entendimento só é válido, pois, ao falar sobre o tema, dois grandes princípios constitucionais são postos a prova e, como muitos acreditam, são denegridos: o principio da dignidade da pessoa humana e o principio da inviolabilidade do direito à vida. Esses seriam, para muitos, os fatores que tornariam a eutanásia um crime.

A dignidade da pessoa humana não só é um dos princípios trazidos pela Constituição, como também está elencada no art. $1^{\circ}$, inciso III, da CF/88 como um dos fundamentos em que a Carta Magna é baseada. Considerada o princípio-matriz de todos os direitos fundamentais, a dignidade da pessoa humana deve ser entendida, nas palavras de Gonçalves (2012, ON-LINE), como um "princípio relacionado com o respeito a direitos fundamentais inerentes à própria pessoa, tais como a vida, a intimidade, a liberdade, a honra e a autodeterminação da própria vida, exigindo respeito das demais pessoas e do Estado". Por ser considerado o princípio-matriz, algumas correntes doutriná- 
rias entendem que todos os princípios - incluindo o princípio da inviolabilidade do direito à vida - derivam deste e, por este motivo, proteger a vida e impedir a prática de atos que possam violá-la é proteger a dignidade da pessoa humana.

O segundo princípio que a prática da eutanásia, em tese, macularia, é o princípio da inviolabilidade do direito a vida. Para a doutrina constitucionalista, esse direito fundamental se divide em duas acepções:

Em sua acepção negativa, consiste no direito assegurado a todo e qualquer ser humano de permanecer vivo. [...] A acepção positiva costuma ser associada ao direito a uma existência digna, no sentido de ser assegurado ao indivíduo o acesso a bens e utilidades indispensáveis para uma vida em condições minimamente dignas. (NOVELINO, 2014, p. 26).

É, sem duvidas, um dos mais importantes princípios, pois sem a vida é impossível desfrutar de outros direitos e garantias fundamentais. 0 direito de continuar vivo é considerado por muitos um direito absoluto. A prática da eutanásia, mesmo que por motivos nobres e com a permissão da vítima, seria uma grande violação a esse principio, pois coloca em dúvida a ideia da disponibilidade desse direito e cria a suspeita sobre a existência de outra garantia: a de uma morte digna. Tal discussão será feita no capítulo seguinte.

\section{CRIME OU ATO DE PIEDADE?}

Antes de concluir o presente artigo, é mais do que necessário discutir, para provocar uma reflexão acerca da natureza da eutanásia e da forma com que a prática é tratada no direito brasileiro, os princípios tratados no capítulo anterior, pois, como todo tema polêmico, a eutanásia movimenta fortes argumentos contra e a favor de sua prática.

Aqueles que são contra o procedimento, alegam, principalmente, motivos religiosos e éticos. É de entendimento geral que a religião exerce um grande papel na sociedade, papel que se torna ainda maior quando ultrapassa o campo social e adentra no politico. Desta forma, o principal discurso em objeção à eutanásia prega que a vida é um bem dado por Deus e que só este teria o direito de tirá-la. Mesmo tendo consciência das causas que levariam alguém a tomar uma medida tão drástica quanto abdicar da própria vida - no caso do suicídio assistido, ou tirar a vida de outra pessoa - no caso do homicídio piedoso - aqueles contra a prática enxergam e entendem o preciosismo da vida e consideram-na um direito absoluto e indisponível.

No campo da ética, focando na ética médica, graças ao Juramento de Hipócrates - responsável por ditar um padrão moral nas atitudes médicas e que em alguns de seus trechos condena qualquer artificio que venha a tirar a vida ou apressar a morte de algum enfermo - tinha-se o entendimento de que a eutanásia, assim como o aborto são atividades que devem ser evitadas ao máximo. Nos dias atuais, houve uma leve mudança no juízo feito sobre o tema. A eutanásia passiva - ou ortotanásia, uma omissão que interrompe os mecanismos que prolongam a vida do paciente (GONÇALVES, 2012) - e o suicídio assistido vêm ganhando defensores dentro da classe médica. No entanto, a eutanásia ativa - consistente na real interrupção da vida continua sendo considerada um homicídio.

\begin{abstract}
A eutanásia passiva vem adquirindo vários defensores (o desligamento de aparelhos que apenas prolongam a vida de doentes em estágio terminal, sem diagnóstico de recuperação), assim como o suicídio assistido. Alguns falam que a eutanásia ativa (o Estado - médico - provocando a morte) seria homicídio. (LENZA, 2014, p. 1071).
\end{abstract}

A favor da eutanásia temos argumentos com a mesma base principiológica daqueles, citados no capítulo anterior, ou seja, os mesmos usados para criminalizar a prática. Primeiramente, é importante deixar claro que todo ser humano em posse de suas faculdades mentais reconhece e admite o valor da vida. 0 que se discute quando se é a favor da eutanásia é a linha tênue entre o direito e o dever de viver. 
Como já visto anteriormente, o princípio da dignidade da pessoa humana assevera nada mais do que o óbvio. Todo ser humano tem direito a todos os fatores que proporcionem a ele uma vida digna e, quando falamos em vida digna estamos incluindo, também, uma morte digna, dando poder ao ser humano de decidir quando e de que forma quer morrer. Não se pode negar a um doente sem chances reais de recuperação o direito de optar por interromper sua vida, quando esta não se encontra tão digna quanto o ideal.

Além disso, precisamos falar sobre o direito à vida. No capítulo anterior o direito em questão é citado como sendo uma das mais importantes garantias constitucionais. Sabemos que ele abrange, em sua magnitude, o direito de continuar vivo e muitos acreditam que ele seja um dos poucos direitos realmente indisponíveis e absolutos. Entretanto, é necessário verdadeiramente compreender a inexistência de direitos absolutos e, inclusive, considerar a disponibilidade de alguns perante outros.

0 já citado princípio da relatividade dos direitos nos ensina que quando existe um conflito entre dois princípios, deve haver a relativização deles. Neste caso, podemos dizer que o direito à vida entraria em conflito com a dignidade da pessoa humana e, fazendo uma interpretação extensiva, o direito à vida entraria em conflito com seu próprio conceito. 0 direito à vida não abrange apenas o direito de permanecer vivo, mas também o direito de possuir uma vida digna.

Desta forma, o mesmo questionamento lançado para o princípio da dignidade da pessoa humana pode ser aplicado aqui. É nítido que, para alguns, não existe dignidade em viver uma vida marcada por uma doença incurável ou onde seu corpo não consegue mais reagir com toda a potência de outrora. A dignidade é um conceito subjetivo e cada indivíduo sabe onde mora a sua, onde começa e onde termina.

Assim, quando houvesse a permissão do paciente, ou ao menos de sua família, não se deveria imputar pena a alguém que, movido pelo sentimento de compaixão, ajuda a interromper o sofrimento do enfermo. A vontade da pessoa deve ser levada em consideração, pois a dignidade e direito à vida, são direitos personalíssimos e, por conseguinte, intransmissíveis. Em outras palavras, como já dito, cada um sabe o significado que dignidade tem para si. Não é certo que o Estado diga quando as pessoas têm ou não que ficar vivas, mesmo quando a vontade delas é contrária. 0 direito à vida não pode se confundir com o dever de viver.

Além disso, se faz necessário lembrar o princípio da autonomia, que tem sua base no respeito à vontade humana sobre o que deve ser feito em sua vida.

\begin{abstract}
0 argumento moral para a legislação sobre a eutanásia voluntária parece basear-se principalmente no apelo ao princípio de autonomia, ou seja, visto que as pessoas têm direito moral de tomar decisões a respeito de sua vida, a lei deve respeitar esse direito e não colocar obstáculos às formas de suas decisões de pôr fim à vida com auxílio de outrem. (PESSINI, 2004, p. 192 apud ABREU, 2015).
\end{abstract}

Por fim, é importante deixar claro que, assim como todo tema polêmico, a eutanásia está longe de ser um assunto pacificado. Existem inúmeros argumentos contra e a favor e, antes que o ordenamento brasileiro tome alguma posição quanto ao assunto, é preciso levar em consideração todos eles. A eutanásia lida com a vida humana e é fato que assunto mais sensível não há.

\section{CONCLUSÃO}

Em observância aos fatos anteriormente expostos, podemos concluir que apesar de ser uma grande polêmica nos tempos atuais, a eutanásia era um procedimento massivamente realizado na antiguidade e praticado por diversas culturas - o que demonstrava um consenso quanto à natureza benéfica da prática. Hoje em dia, ela esbarra em dogmas morais e religiosos e, além disso, no Brasil, na falta de legislação que legalize ou, ao menos, regulamente a prática. É interessante lembrar que o termo eutanásia diz respeito apenas 
ao procedimento que verdadeiramente provoca a morte de um enfermo, sendo a ortotanásia, a distanásia e o suicídio assistido coisas diferentes, o que torna ainda maior a necessidade de legislação pertinente ao assunto.

Ao considerar a sensibilidade presente no tema, a grande conclusão a ser feita é a da existência de uma necessidade crescente de reflexão social e posicionamento jurídico quanto à eutanásia. No nosso sistema penal é notável a falta de referências concretas ao assunto e às mudanças propostas no anteprojeto do código penal estão bem longe de serem ideais. Além disso, é preciso fazer com que a sociedade reflita sobre o assunto para que, desta forma, desmistifique 0 instituto da eutanásia e comece a enxergá-lo como a melhor saída em alguns casos.

A morte é um assunto assustador em muitas culturas. Não saber o que acontece de verdade depois do término da nossa presença mundana causa susto e medo, fazendo com que determinados assuntos virem tabu. O ser humano sempre temeu o desconhecido e, por esse motivo, criou-se uma cultura de manter a vida apesar de qualquer coisa, até quando ela deixa de valer à pena e sua dignidade é perdida.

\section{REFERÊNCIAS}

ABREU, F.S. Eutanásia e legislação penal. 2015. Disponível em: <http://www.ambito-juridico.com. br/site/?n_link=revista_artigos_leituraqartigo_ id=16522 >. Acesso em: ago. 2016.

CABETTE, E.L.S. Direito penal: parte especial I. São Paulo: Saraiva, 2012.

CARVALHO, G. M. de. Aspectos jurídicos-penais da eutanásia. IBCCRIM, 2001.

ESTEFAM, A.; GONÇALVES, V.E.R. Direito penal: parte geral esquematizado. 4.ed. São Paulo: Saraiva, 2015.
GONÇALVES, M.D.A.P.; ALMEIDA, S.L. de.

\section{Breves reflexões sobre a eutanásia e seu} sancionamento. 2012. Disponível em: <http:// www.ambito-juridico.com.br/site/index.php?n link=revista_artigos_leitura\&artigo_id=11733>. Acesso em: ago. 2016.

HASSEMER, W. Direito penal libertatório. Belo Horizonte: Del Rey, 2007.

JESUS, D.E. Temas de direito criminal. $2^{\mathrm{a}}$ série. São Paulo: Saraiva, 2001.

KOVÁCS, M.J. Educação para a morte: temas e reflexões. São Paulo: Casa do Psicólogo, Fapesp, 2003.

LENZA, P. Direito constitucional esquematizado. 18.ed. São Paulo: Saraiva, 2014.

MAGALHÃES, B.M.C.C. Eutanásia: origem, ramificações e outras peculiaridades. 2014. Disponível em: <http://www.ambito-juridico.com. br/site/?n_link=revista_artigos_leitura\&artigo_ $\mathrm{id}=14519>$. Acesso em: ago. 2016.

MARINS, A.L.F. A eutanásia no ordenamento jurídico brasileiro. 2013. Disponível em: <http:// www.ambito-juridico.com.br/site/?n_link=revista_ artigos_leitura\&artigo_id=12717>. Acesso em: ago. 2016.

MENEZES, E.C. Direito de matar: eutanásia. 2.ed. Rio de Janeiro: Freitas Bastos, 1977.

NOVELINO, M. Manual de direito constitucional. 9.ed. Rio de Janeiro: Forense; São Paulo: Método, 2014.

VILLAS-BÔAS, M.E. A ortotanásia e o direito penal brasileiro. Revista Bioética, v.16, n.1, 2009. 
Data da submissão: 14 de novembro de 2016 Avaliado em: 10 de dezembro de 2016 (Avaliador A) Avaliado em: 02 de janeiro de 2017 (Avaliador B) Aceito em: 06 de janeiro de 2017
1 Graduanda em Direito pela Universidade Tiradentes - UNIT; Integrante do Grupo de Pesquisa Gênero, Família e Violência do Diretório de Pesquisa do CNPq, sob orientação da Professora Mestra Grasielle Borges Vieira de Carvalho. E-mail: carolsilvaporto@gmail.com

2 Doutora pela Universidade Nova de Lisboa na Faculdade de Ciências Sociais e Humanas em Ciência Política especialidade em Política Pública; Mestre em Ciência Política e Relações Internacionais especialidade em Globalização e Ambiente pela Universidade Nova de Lisboa na Faculdade de Ciências Sociais e Humanas; Bacharel em Comunicação Social pela Universidade Tiradentes - UNIT; Professora Universitária; Investigadora do Observatório Político; Membro do Grupo de Pesquisa-CNPQ “Novas Tecnologias e o Impacto nos Direitos Humanos”. E-mail: cleciaferreira.unit@gmail.com 